\title{
Potensi Pengembangan Ekowisata Di Kecamatan Sirah Pulau Padang Ditinjau dari Sektor Perkebunan Masyarakat
}

\author{
Ari Sugiarto \\ Email: sugiartoari13@gmail.com
}

\begin{abstract}
Abstrak
Setiap wilayah memiliki potensi untuk dikembangkan menjadi kawasan ekowisata. Pengembangan ekowisata pada suatu wilayah dapat memberikan dampak kemajuan yang besar terhadap suatu wilayah. Salah satu sektor yang berpotensi untuk dikembangkan menjadi kawasan ekowisata yaitu perkebunan. Kecamatan Sirah Pulau Padang memiliki perkebunan yang cukup luas. Perlu dilakukan penelitian untuk melihat potensi pengembangan ekowisata di Kecamatan Sirah Pulau Padang ditinjau dari sektor perkebunan masyarakat. Penelitian ini dilakukan dengan melakukan pengamatan pada perkebunan masyarakat dan dikaitkan dengan potensi pengembangan ekowisata. Hasil dari penelitian menunjukkan di Kecamatan Sirah Pulau Padang berpotensi untuk dikembangkan menjadi kawasan ekowisata musiman.
\end{abstract}

Kata kunci: Ekowisata, Kecamatan Sirah Pulau Padang, Perkebunan

\section{Pendahuluan}

Pengembangan ekowisata pada suatu wilayah dapat membantu dalam pengembangan masyarakat pedesaan, konservasi keanekaragaaman hayati, pendidikan konservasi (Eshun, 2010), konservasi budaya (Friedman, 2009), dan peningkatan ekonomi (Ummiroh dan Rini, 2013).

Setiap wilayah memiliki potensi ekowisata masing-masing yang dapat dikembangkan. Pengembangan ekowisata ini akan memberikan dampak yang besar untuk kemajuan suatu wilayah. Menurut Klak (2007), salah satu potensi yang dapat dikembangan untuk ekowisata yaitu pertanian. Selain itu juga, sektor perkebunan juga dapat dikembangkan menjadi kawasan ekowisata.

Kecamatan Sirah Pulau Padang merupakan salah satu kecamatan yang ada di Kabupaten Ogan Komering Ilir, Provinsi Sumatera Selatan. Menurut Sugiarto (2018), Kecamatan Sirah Pulau Padang terdiri dari beberapa ekosistem yaitu ekosistem perkebunan, persawahan, sungai, dan permukiman. Melihat adanya potensi pengembangan ekowisata di sektor perkebunan, perlu dilakukan penelitian mengenai potensi pengembangan ekowisata di Kecamatan Sirah Pulau Padang ditinaju dari sektor perkebuanan masyarakat. Manfaat dari penelitian ini dapat memberikan data mengenai potensi pengembangan ekowisata di Kecamatan Sirah Pulau Padang.

\section{Metode Penelitian}

Penelitian ini dilaksanakan pada bulan Desember 2018 bertempat di Kecamatan Sirah Pulau Padang, Kabupaten Ogan Komering Ilir, Sumatera Selatan. Penelitian ini dilakukan dengan melakukan pengamatan pada perkebunan masyarakat. Variabel pengamatan yaitu jenis tanaman yang ditanam dan berpotensi untuk mendukung pengembangan ekowisata serta perkiraan musim panennya. Setelah didapatkan variabel hasil pengamatan, dikaitkan dengan potensi pengembangan ekowisata.

\section{Hasil dan Pembahasan}

Hasil pengamatan pada perkebunan masyarakat, didapatkan tanaman yang berpotensi untuk mendukung pengembangan ekowisata yaitu: 
Tabel 1. Jenis tanaman yang ditanam di perkebunan masyarakat dan perkiraan musim panennya

\begin{tabular}{|c|c|c|}
\hline Tanaman & Nama lokal & Perkiraan musim panen \\
\hline $\begin{array}{l}\text { Durio zibethinus Rumph. ex } \\
\text { Murray }\end{array}$ & Duren & Desember-Januari \\
\hline Lansium domesticum Corr. & Duku & Februari-Maret \\
\hline Garcinia mangostana L. & Mangges & Desember-Januari \\
\hline Nephelium lappaceum L. & Rambutan & Januari-Februari \\
\hline $\begin{array}{l}\text { Baccaurea motleyana Müll. } \\
\text { Arg. }\end{array}$ & Rambai & Januari-Februari \\
\hline Bоиеа macrophylla Griff. & Raman, Ganderie & Januari-Februari \\
\hline
\end{tabular}

Potensi pengembangan ekowisata di Kecamatan Sirah Pulau Padang jika ditinjau dari sektor perkebunan masyarakat memiliki potensi pengembangan ekowisata musiman. Berdasarkan hasil pengamatan pada perkebunan masyarakat, ekowisata musiman ini dapat berlangsung pada bulan Desember sampai dengan Maret. Kegiatan ekowisata musiman ini dapat isi dengan beberapa kegiatan seperti berkemah di perkebuanan, outbound, menikmati buahbuahan, ataupun belajar berkebun dari masyarakat. Kegiatan itu semua dapat dilakukan dalam satu kunjungan ekowisata di Kecamatan Sirah Pulau Padang. Pemandu kegiatan ekowisata tentunya berasal dari masyarakat lokal yang berpendidikan, hal ini bertujuan agar pemandu ekowisata memiliki pengetahuan yang banyak tentang lingkungan sekitar serta memberikan kemudahan dalam berkomunikasi dengan ekowisatawan. Selain itu, masyarakat dapat menyediakan cendera mata untuk ekowisatawan yang dapat berupa buah-buahan hasil panen ataupun kerajinan tangan yang dibuat oleh masyarakat. Masyarakat juga dapat meminta masukan dan saran dari ekowisatawan setelah mengikuti kegiatan ekowisata untuk peningkatan ekowisata di Kecamatan Sirah Pulau Padang. Menurut Klak (2007), beberapa cara untuk mengembangkan kegiatan pariwisata agar dapat menjadi bagian mendasar dari pembangunan daerah terpadu seperti dengan mempromosikan pertanian lokal yang sehat, lahan, keahlian, pengembangan keterampilan profesional, diversifikasi pekerjaan, solidaritas, dan kebanggaan masyarakat. Menurut Sugiarto dan Hanifa (2018), Lansium domesticum Corr. yang terdapat di Kabupaten Ogan Komering Ilir biasa dikenal dengan duku komering . Ini dapat menjadi daya tarik lainnya untuk pengembangan ekowisata di Kecamatan Sirah Pulau Padang.

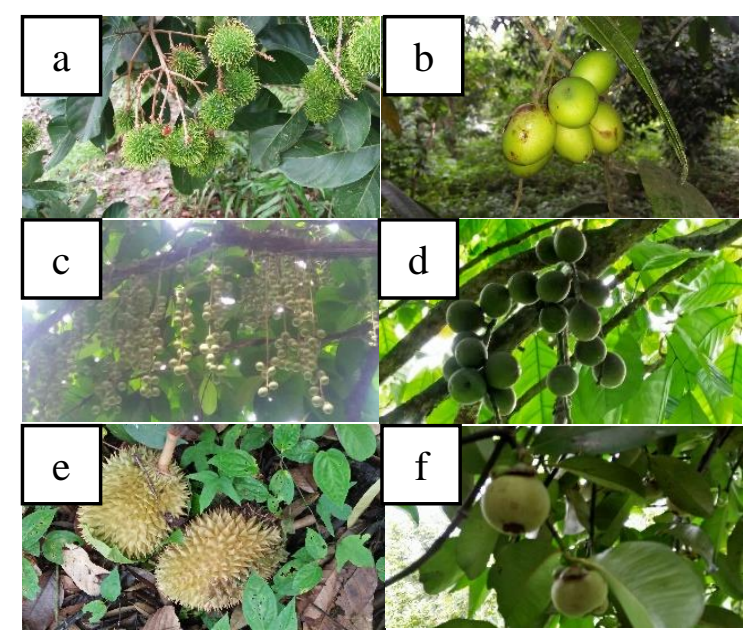

Gambar 1. Buah a. Nephelium lappaceum, b.Baccaurea motleyana, c. Bouea macrophylla, d. Lansium domesticum, e. Durio zibethinus, dan f. Garcinia mangostana

Pengembangn ekowisata di Kecamatan Sirah Pulau Padang dapat terlaksana lebih cepat dengan campur tangan pemerintah, dalam hal ini pemerintah dapat membantu menyediakan dana untuk pembangunan fasilitas pendukung kegiatan ekowisata dan membantu dalam mempromosikan kegiatan ekowisata yang ada di Kecamatan Sirah Pulau Padang. Terlaksananya 
kegiatan ekowisata di Kecamatan Sirah Pulau Padang dapat membantu peningkatan perekonomian masyarakat. Hal ini didukung oleh Eshun (2010), pengembangan ekowisata dapat berkontribusi terhadap pengembangan masyarakat pedesaan, konservasi keanekaragaman hayati dan pendidikan konservasi. Menurut Ummiroh dan Rini (2013), ekowisata tidak hanya meningkatkan nilai ekonomi tetapi memiliki nilai tambah. Selain itu menurut Friedman (2009), manfaat pengembangan ekowisata diharapkan dapat membatu pembangunan, memberikan perlindungan lingkungan, dan konservasi budaya. Namun menurut Tran dan Do (2011), adanya ekowisata pada suatu wilayah dapat menyebabkan banyak dampak negatif bagi sumber daya alam, ekologi, dan lingkungan setempat.

\section{Kesimpulan}

Potensi pengembangan ekowisata di Kecamatan Sirah Pulau Padang jika ditinjau dari sektor perkebunan masyarakat sangat mendukung untuk dikembangkan menjadi kawasan ekowisata musiman. Tanaman yang banyak ditanam pada perkebunan masyarakat ini yaitu Durio zibethinus, Lansium domesticum, Garcinia mangostana, Nephelium lappaceum, Baccaurea motleyana, dan Bouea macrophylla yang berbuah musiman. Waktu kunjungan ekowisata musiman di Kecamatan Sirah Pulau Padang dapat belangsung dari bulan Desember sampai dengan Maret.

\section{Daftar Pustaka}

Eshu, G. 2010. Ecotourism Development in Ghana: A Postcolonial Study with Focus on Boabeng-Fiema Monkey Sanctuary and Kakum National Park. Tesis. University of Leicester, Department of Geography.

Friedman, V.S. 2009. Ecotourism in Dominica: Studying the
Potential for Economic Development, Environmental Protection and Cultural Conservation. Island Studies Journal. 4(1): 3-24.

Klak, T. 2007. Sustainable Ecotourism Development in Central America and the Caribbean: Review of Debates and Conceptual Reformulation. Geography Compass. 1(5): 1037-1057.

Sugiarto, A. 2018. Inventarisasi Belalang (Orthoptera: Acrididae) di Perkebunan dan Persawahan Desa Serdang Menang, Kecamatan Sirah Pulau Padang, Kabupaten Ogan Komering Ilir. (Online). https://doi.org/10.31227/osf.io/ dqprh. Diakses pada tanggal 1 Januari 2018.

Sugiarto, A dan Hanifa, M. 2018. Ekologi Duku Komering. (Online) https://www.researchgate.net/p ublication/328333944_EKOL OGI_DUKU_KOMERING. Diakses pada tanggal 1 Januari 2019.

Tran, H.M.L dan Do, Q.A. 2011. Impact of Ecotourism: A Study on the Environmental Impact of Ecotourism in Can Gio Mangrove Biosphere, Vietnam. Skripsi. Laurea University of Applied Sciences, Department of Hospitality Management.

Ummiroh, I.R dan Rini, H. 2013. AgroEcotourism Management through Cooperative Based Coffee Plantation Commodity to Increase Welfare of Coffee Farmer. Journal of Economics, Business and Management. 1(4): 347-349. 